\title{
Product bundling and advertising strategy for a duopoly supply chain: a power-balance perspective
}

\author{
Sarat Kumar Jena ${ }^{1}$ (D) $\cdot$ Abhijeet Ghadge $^{2}$ (D) \\ Accepted: 3 November 2020 / Published online: 9 December 2020 \\ (c) The Author(s) 2020
}

\begin{abstract}
The paper studies product bundling in a duopoly supply chain network under the influence of different power-balance structures, bundling decisions and advertising efforts on total supply chain profit. Mathematical models comprising two manufacturers and a single retailer are developed to capture the impact of bundling policy and advertisement strategy under three power-balance structures, namely Manufacturer Stackelberg, Retailer Stackelberg and Vertical Nash. Following game theory models and numerical examples, the study found that the total profit of the supply chain is undifferentiated under the manufacturer Stackelberg and Vertical Nash case in the manufacturer bundling and retailer bundling strategies. However, total supply chain profit under manufacturer bundling strongly dominates under retailer bundling in Retailer Stackelberg and Vertical Nash, and remains valid under multiple settings of market size, price elasticity and advertising elasticity. It is also found that manufacturer bundling is significantly affected by advertising effort compared to retailer bundling. The study contributes to the literature interfacing supply chain and marketing by studying bundling policy and advertising strategy simultaneously for homogenous products, under various power-balance structures and price competition.
\end{abstract}

Keywords Bundling · Competition · Advertising · Supply chain · Pricing · Game theory

\section{Introduction}

Bundling is a popular strategy adopted in marketing, which combines two or more products or services to maximise the chain's profit (Bakos and Brynjolfsson 1999; Stremersch and Tellis 2002; Lancioni et al. 2005), though the pricing and advertising of these bundles remains an extremely challenging task. A bundle can consist of a group of complementary products (e.g., shampoo and conditioner; pizza and toppings), vertically differentiated products (e.g., DVD and Blu-ray disk bundle), independently valued products (e.g., coffee with teacup) or substitute products (e.g., two-ticket combination to a successive football match). They

$\triangle$ Abhijeet Ghadge

Abhijeet.Ghadge@Cranfield.ac.uk

1 Xavier Institute of Management, Xavier University, Bhubaneswar, India

2 Centre for Logistics and Supply Chain Management, School of Management, Cranfield University, Bedford, UK 
can also be made of multiple units of the same products. Bundling can involve product bundling or price bundling (Beheshtian-Ardakani et al. 2018). Product bundling defines integrated products that provides extra value to the customers and price bundling consists of a package sold at a discount rate, without any integration of the goods and/or services involved (Adomavicius et al. 2015; Giri et al. 2020; Jeitschko et al. 2017; Vamosiu 2018). In addition, depending on the number of items bundled, the nature of such items and the degree of variations, bundling can also reduce consumer costs (Yan et al. 2014).

Product bundling offers economic scale as bundle choices and size are significant for both buyer and seller. Typically, three types of product bundling strategies are employed by firms: component strategy, where the retailer or manufacturer offers only the component-wise product; pure bundling strategy, where the retailer/manufacturer sells the product in a bundle, for instance, the television content provider Videocon typically offers its television subscribers free additional access (regional channel) on any devices; and a mixed strategy where the seller offers component as well as bundle products, for example, the selling of hardcover and Kindle editions of books on Amazon independently as well as bundles of hardcover and Kindle editions together (Meyer and Shankar 2016; Ma and Mallik 2017). Amazon's bundle of hardcover and Kindle edition of any book is an example of a retail-produced bundle. When a manufacturer adopts an appropriate bundling approach, it is essential to adjust their sales strategy in response to the bundling. However, in today's competitive business environment, it is typical that a retailer will try to sell bundled products produced by two or more manufacturers to attract more demand (Yan et al. 2014). Therefore, in order to maximise its selling, the firm involves an advertising campaign to promote the bundling products.

Advertising helps to promote the characteristics of the bundle product quality, attractive price, discount and other promotions to encourage consumers to buy. Furthermore, most studies discuss that advertising plays a vital role in demand creation and market expansion (Mesak and Darrat 1993; Godes et al. 2009; Liu et al. 2014; Baykasoğlu et al. 2017; Chakraborty et al. 2018). The seller uses advertising to create awareness about the product, thereby increasing product sales and profit. Almost every company keeps a significant portion of its total budget for advertising (Yenipazarli 2015; Jena et al. 2017). According to He et al. (2011), in 2007, manufacturers spent over $\$ 25$ billion on advertising, compared to $\$ 5$ billion in 2000 . However, it is also crucial for a seller to decide the optimal price and advertising effort of a bundle product, for maximising the sales revenue in a supply chain network. Merely selling high quality products is not sufficient in the current competitive business environment; thus, multiple marketing strategies are adopted by businesses to increase their profitability. Due to the potential impact of such strategies on product price and demand, competition between manufacturers and retailers on bundling price and advertising effort is significantly affected.

Most studies, to date, focus on various models of bundling in supply chain management (e.g., Arora 2008; Cataldo and Ferrer 2017; Giri et al. 2020; Vamosiu 2018; Lin et al. 2020); though very limited studies have addressed bundling price policy in the supply chain under competition (Chakravarty et al. 2013; Chen and Wang 2015; Ma and Mallik 2017; Vamosiu 2018). For instance, Yan et al. (2014) discuss the bundling pricing policy under a single manufacturer and retailer. In addition, Vamosiu (2018) analysed a two-product supplier's incentives to bundle their products considering pure bundling, mixed bundling and independent bundling under imperfect competition against one of their products. None of these works consider the impact of the advertisement element while considering manufacturer bundling and retailer bundling under dual supply chain competition. Simultaneous consideration of product bundling and advertising efforts on internal supply chain competition is distinctly lacking in the academic literature. Therefore, the study proposes to develop an analytical model to optimise total supply chain profit by studying product bundling and advertising 
strategy in a duopoly competitive supply chain environment. More importantly, the study addresses the effect of the power balance between two manufacturers and a retailer on optimal product prices, advertising costs and total supply chain profit.

This paper considers three power-balance structures/scenarios under product bundling and advertising strategy between two manufacturers and a retailer in the supply chain network. There are three possible power-balance structures/scenarios concerning strategic interactions between a manufacturer and a retailer, namely: (1) Manufacturer Stackelberg (2) Retailer Stackelberg, and (3) Vertical Nash (Lu et al. 2011). In general, manufacturers possess more bargaining power than retailers in a market (Ailawadi et al. 1995; Ma et al. 2019), where each manufacturer chooses the wholesale price using the response function of the retailer and by considering the observed wholesale price of the competitors' product. Such interactions between supply-chain partners will follow a Manufacturer Stackelberg. On the other hand, in a Retailer Stackelberg, the retailer possesses more negotiating power due to its dominating size or customer loyalty in the supply chain network. In Vertical Nash, neither the manufacturer nor the retailer possesses a larger bargaining power in the negotiation. In this paper, two strategies for the production of a bundle are considered: manufacturer bundling, where a manufacturer produces the bundle; and, retailer bundling, where the manufacturer produces individual products and then retailer produces the bundle from such products.

The paper seeks to address the following research questions:

1. What is the optimal bundling price and advertising expenditure under three strategic power-balance structures between manufacturers and retailer?

2. How does the price competition and advertising expenditure influence the total supply chain profit under retail bundling and manufacturer bundling?

The rest of the paper is structured as follows. A brief review of the literature is covered in Sect. 2. Section 3 discusses key notations and assumptions of the modelling framework. Comparison of the results is presented in Sect. 4, followed by a numerical example to illustrate the working of the model in Sect. 5. Section 6 discusses sensitivity analysis and managerial insights. The paper concludes with a discussion on key findings, contribution and future research directions.

\section{Literature review}

This section provides a brief review on key concepts (bundling, competition and advertisement) interfacing with marketing and supply chain literature.

\subsection{Bundling in marketing and supply chain}

Marketing and supply chain management literature around bundling mainly considers a single firm in vertical and horizontal supply chains. Hanson and Martin (1990) developed an optimisation model for the single firm bundle pricing problem. For simplicity, it would be useful to allow the marginal cost of a bundle product. Bakos and Brynjolfsson (1999) studied the bundling schemes of information goods and found that large bundles may bring significant advantage in the competition for upstream content. McCardle et al. (2007) explored the effect of bundling on channel profit, considering two standard retail products (basic and fashion) and observed that bundling on profitability relies on individual product demand. Pan and Honhon (2012), exploring the optimal bundling and pricing strategy for a firm selling vertically differentiated products, discovered the conditions under which a pure bundling 
and mixed bundling strategy are optimal. Meanwhile, Li et al. (2013) addressed the bundling sale considering customer heterogeneity and found that mixed partial bundling schemes are superior when compared with the component strategy for information goods.

Girju et al. (2013), while identifying the effect of channel interaction on the supply chain members' bundling decision, found that the pure component strategy is the best strategy in most cases. Cao et al. (2015) addressing the retail bundling strategy in a distribution channel, observed that the manufacturer's marginal production plays an important role in channel profit considering retailers' bundling decisions. Prasad et al. (2015), addressing the impact of mixed bundling strategy against reserved product pricing, found that reserved product pricing profitability depends on the fraction of myopic consumers. Ma and Mallik (2017) studied bundling of vertically differentiated products in a supply chain, considering a single manufacturer and a single retailer under retailer bundling and manufacturer bundling strategies. They found that total supply chain profit under manufacturer bundling dominates retail bundling. Using mixed-integer nonlinear programming, Cataldo and Ferrer (2017) analysed a problem faced by a firm in a single market segment to determine the optimal composition and pricing of multiple bundles.

Pure bundling and mixed bundling strategies are better than component strategy according to $\mathrm{Xu}$ et al. (2018), who addressed the firm's optimal pricing and quality policy under three bundling strategies (i.e., no bundling, pure bundling and mixed bundling). Their results show that pure bundling proves more profitable compared to any other strategy. Hence, in this paper, we consider pure bundling in a supply chain to identify how optimal bundling price and supply chain network/channel profit are affected by price competition. Hurkens et al. (2019) discuss how bundling affects price competition by considering an asymmetric duopoly, where one firm has symmetric dominance in all of its products. They found that dominant firms benefit from a positive demand size effect of bundling. Taleizadeh et al. (2019) studied supply chain optimisation considering two pricing strategies such as pricing of complementary products without a bundling policy, and pricing of complementary products under a bundling policy. In the bundling policy, the wholesale and retail prices are lower than the prices without bundling.

Zhang et al. (2019) analysed the return and refund policy for product and core service bundling, considering two-stage demand uncertainty under a dual supply chain. Consumers can decide to return the default profit through a direct channel. Meanwhile, Liu et al. (2020) studied a two-stage supply chain consisting of two manufacturers and one retailer, while considering imperfect, complementary products. More recently, Heydari et al. (2020) discussed coordinated and non-monetary sales promotion in a supply chain, considering the buy one get one free (BOGO) scheme. They found that a coordinated BOGO scheme provides higher supply chain profitability and demand.

Furthermore, Zhou et al. (2020) evaluated the impact of bundling and pricing strategies of two competing firms under a multi-stage game theoretic model. Here, one firm acts as a leader to determine the product price, before the other firm acts as a follower. In addition, they consider that one firm offers the bundle product, while the other firm offers separate products under an equilibrium system.

\subsection{Competition in supply chains}

There is a vast amount of literature on competition between different supply chain networks; however, the focus of this paper is on competition within supply chain partners. Interestingly, most of the existing literature discusses chain competition, considering inventory theory and 
product availability (Mahajan and Van Ryzin 2001). Earlier work by Choi (1991) shows that all the members in the supply chain, including customers, are better off when there is no single dominating player in the supply chain network. Choi (1996), extended the work by considering the effect of price competition and advertisement simultaneously on bundling decision, finding that most consumer goods are retail-dominated in a chain.

Meanwhile, Chen (1997) studied the practice of product bundling; in this case, author developed equilibrium theory of product bundling, considering perfect competition under a product-differentiation device. Furthermore, Opornsawad et al. (2013) addressed the pricing competition strategy for a commoditised product such as drinking water and generic pharmaceutical products under different bargaining power scenarios. Their model considers a duopoly manufacturer and a common retailer for analysing the impact of power balance between manufacturer and retailer under a competitive environment. Roy et al. (2018) studied a two-echelon supply chain considering duopoly retailers and a common manufacturer under price-sensitive demand with random arrival of customers. They also compared different Stackelberg models, such as Bertrand and Cournot, for maximising the profit of the players in the chain. It is observed that competition between original equipment manufacturers can be better off cooperating as supply chain partners (Pun 2015).

Zhou (2017) proposed a framework for studying pure bundling considering consumer valuation under an oligopoly market. The model suggests how consumer valuation dispersion affects price competition. Meanwhile, Ali et al. (2018) studied the effect of potential market demand disruption on price and service level for competing retailers considering a Manufacturer Stackelberg game model. They analysed the effect of demand disruption under centralised and decentralised scenarios and found that price and service level investment are significantly influenced by demand disruption. Recently, Vamosiu (2018) examined bundling strategy, considering two product sellers of a differentiated product under imperfect competition and found that pure bundling emerges as the optimal pricing strategy and competitors maximise their profit under a mixed bundling strategy.

\subsection{Advertising in supply chains}

Earlier works on bundling advertisements explored the relationship between the traditional practice of bundling advertisements and content provision on the internet (Yuan et al. 1998). Koschat and Putsis (2002) studied audience characteristics and bundling considering the hedonic analysis of magazine and advertising strategy. Huang et al. (2002) addressed an interesting cooperative advertising model using a game theory approach, where the manufacturer paid for the brand name investment and shared some proportion of the local advertising cost incurred by the retailer. Yue et al. (2006) studied cooperative advertising in a manufacturer-retailer supply chain considering price deduction by the manufacturer to the customer. Bundling with advertising provides higher performance than bundling without advertising, as evidenced by Yan et al. (2014) who studied the value of the bundling strategy with advertising for identical and complementary products.

The simultaneous consideration of bundling policy, advertising strategies and competition in a supply chain has not been explored in the extant literature. The closest possible work, previously attempted is by Vamosiu (2018), which explores optimal bundling under imperfect competition; however, this does not attempt a product bundling policy under various power balances between the manufacturer and retailer. Moreover, Cao and $\operatorname{Ke}(2019)$ studied cooperative advertising considering a single manufacturer and retailer under cost sharing. 


\subsection{Research gaps}

As observed in the above literature, none of these studies have discussed the effect of price competition and advertising expenditure on the optimal bundling price and total supply chain profit under three strategic power-balance structures between manufacturers and retailers. To fill this evident gap, in this paper, the power balance between two manufacturers and a retailer and its impact on optimal bundle product prices, advertising costs and total supply chain profit are examined under a competitive environment. However, some researchers have discussed the effect of competition on total supply chain profit considering the power balance between manufacturer and retailer. However, they did not consider the effect of different power balances between manufacturers and retailers on total profit under pure bundling strategies.

The research discussed in this paper also differs from Ma and Mallik (2017), Xu et al. (2018), Giri et al. (2020), Yan et al. (2014) and Chakravarty et al. (2013) by simultaneously considering the effect of advertising strategy and competition on bundling decisions under Manufacturer Stackelberg, Retailer Stackelberg, and Vertical Nash cases. Bundling with power balance between manufacturer and retailer under Manufacturer Stackelberg, Retailer Stackelberg, and Vertical Nash strategies, as such, has not been studied adequately in the supply chain and marketing literature.

\section{The model}

The model considers a competitive supply chain consisting of two manufacturers and single retailer (including other stakeholders in the network). Both of these manufacturers sell their products to a common retailer who, in turn, sells the products to the end customer. For modelling purposes, it is assumed that this activity occurs in a single period. The objective of the study is to make bundling decisions under price competition and advertising effort in a supply chain context. As a result, the developed model allows either the manufacturer or retailer to produce the bundle from two similar component products and compare the two scenarios. Here, it is assumed that the distance between each retailer is so large that there is no competition among retailers, thus allowing focus on competition between the two manufacturers. The model considers deterministic demand for each bundled product and is sensitive to two factors: (1) retail price; and, (2) advertising expenditure by the retailer. Note that only the advertising efforts by the retailer are considered. Here, pure bundling strategy with manufacturer bundling and retailer bundling is considered.

The assumption regarding the bargaining power possessed by each seller can influence how the pricing game is solved in this model. The bargaining power of the retailer and manufacturer can have a significant influence on supply chain profit. In this paper three forms of bargaining power within the supply chain are considered: (1) Manufacturer Stackelberg (MS), (2) Retailer Stackelberg (RS), and (3) Vertical Nash (VN). The level of bargaining power possessed by each player (as compared to the other firms) in the supply chain is interpreted by whether the manufacturer or retailer is the leader. The player with more bargaining power has the first-mover advantage (called Stackelberg leader), and the player with less bargaining power would have to respond to the leader's decision. Considering three powerbalance scenarios in the model, the study attempts to explore the effect of bargaining power within the supply chain on the manufacturer and retailer bundling strategy. 
Table 1 Notation and associated description

\begin{tabular}{ll}
\hline Symbol & Description \\
\hline$D_{B i}$ & Demand of bundling product in the market, where $i$ is the manufacturer 1 \\
$c_{B}$ & Unit bundling cost of the bundling product \\
$c 1$ and $c 2$ & Unit manufacturing cost of the components $a$ and $b$ \\
$\alpha_{n}$ & Market size for the bundling product $\left(\alpha_{B}\right)$ and individual product $\left(\alpha_{i}\right)$ \\
$\beta_{n}$ & Price elasticity \\
$\gamma_{n}$ & Cross- price elasticity \\
$\theta$ & Advertising effort (large positive number) \\
$k$ & Advertising sensitivity coefficient \\
$\pi_{r}$ & Profit function of the retailer \\
$\pi_{m i}$ & Profit function of the manufacturer $i$ \\
Decision variables & \\
$p_{B i}$ & Unit selling price of a bundling product for the manufacturer $i$ \\
$w_{B i}$ & Unit wholesale price of a bundling product for the manufacturer $i$ \\
$A$ & Unit advertising cost for selling the bundling product \\
$w_{i}$ & Unit wholesale price of a component for the manufacturer $i$ \\
\hline
\end{tabular}

\subsection{Model notations and assumptions}

Table 1 shows the notations used for the development of the mathematical model. The demand function is sensitive to price and advertising expenditure during mathematical modelling. Subscripts $i, j, s, r, \mathrm{M}$ and $\mathrm{R}$, respectively, to indicate manufacturer 1, manufacturer 2, manufacturer, retailer, manufacturer bundling, and retailer bundling are used throughout paper.

An analytical model is formulated for the supply chain system, where component products are produced by the manufacturer and sold to the retailer under various power balance strategies between manufacturer and retailer. It is essential for the manufacturer to understand the effect of price competition of bundling on manufacturing activities.

Assumption 1 Under retailer bundling, the manufacturer produces a component, and the retailer is responsible for producing the bundle. Whoever in the supply chain produces the bundle incurs the unit bundling cost $c_{B} \geq 0$ (Ma and Mallik 2017). Here, the retailer is not selling any component products to the customer. Let " $m$ " denote the retailer's sales margin. The retail price can then be expressed as $p_{B i}=\left(w_{a i}+w_{b i}\right)+m$ for manufacturer $i$. Bundling consists of two component products whose whole sale price are $w_{a i}$ and $w_{b i}$ for component $\mathrm{a}$ and $\mathrm{b}$, respectively. Here, we have assumed that two components' wholesale prices are equal, such as $w_{a i}=w_{b i}=w_{i}$. As a result, we can consider the retail price can be expressed as $p_{B i}=2 w_{i}+m$ and $p_{B j}=2 w_{j}+m$ for manufacturer $\mathrm{i}$ and manufacturer $\mathrm{j}$, respectively.

Assumption 2 Under manufacturer bundling, the manufacturer produces bundling with a bundling price $w_{B i}(i, j=1,2, i \neq j)$, while the retailer sells these bundling products in component products into the market (Ma and Mallik 2017; Yan et al. 2014). The bundling price is lower than the total price but higher than the component product price (Yan et al. 2014). Considering this assumption, here, the retail price can then be expressed as $p_{i}=w_{B i}-m$ for manufacturer i $(i, j=1,2, i \neq j)$. 
Assumption 3 The unit production cost ( 1 and $\mathrm{c} 2$ ) of the two component products are normalized to zero (Yan et al. 2014; Ma and Mallik 2017).

The manufacturer produces two components and sells them to the retailer. To simplify the computation and the results, comparable to Banciu et al. (2010), Yan et al. (2014), Ma and Mallik (2017), and Xu et al. (2018), we assume that the unit production cost ( $c 1$ and $c 2$ ) of the two component products are normalised to zero; we also assume that the wholesale price of the two component products is the same. The reason for this is that production costs of component products are not decision variables in our model, and the optimal result will not be affected. This is a valid assumption for information goods and many of the examples discussed previously (e.g., CD, DVD, Blu-ray production where the fixed cost of content development significantly exceeds the variable cost of producing a disc). Whereas, in manufacturer bundling, the manufacturer also produces the bundle from the component products and sells these products to the retailer at a unit wholesale price $w_{B}$. For simplicity, the model considers that manufacturers only sell bundling products to the retailer.

Assumption 4 The demand structure is symmetric between two bundled products. Demand for a bundled product is decreasing by the manufacturer's own retail price and increasing with the competitor's retail price. Furthermore, the demand for the bundled product is increasing by the retailer's advertising investment (Yan et al. 2014). Here, the paper considers bundled products exclusively under competition.

The demand function of the bundled product, produced by the manufacturer or retailer, is continuous, deterministic and price (and advertising effort) sensitive and assumed to be in the following form: $D_{B i}=\left(\alpha_{n}-\beta_{n} p_{B i}+\gamma_{n} p_{B j}+k A\right)$. Where $\alpha_{n}>$ $0, \beta_{n}>0, \gamma_{n}>0$, and $k>0, i \rightarrow$ manufacturer $1, j \rightarrow$ manufacturer 2, (where, in short form we represented $i, j=1,2, i \neq j$ ).

Here, to simplify the computation and results comparable to Yan et al. (2014), the market size $\left(\alpha_{B}\right)$ of bundling product and individual product $\left(\alpha_{i}\right)$ are equal $\left(\alpha_{B}=\alpha_{i}=\alpha_{n}\right)$.

Let $p_{B i}$ and $A$ be the selling price and advertising level, respectively. Subscript B is used to denote the bundling product throughout the paper. $\alpha_{B i}$ is the market base (i.e., potential demand offered free of charge). $\beta_{n}$ is the price elasticity of the product, whereas $\gamma_{n}$ represents the cross-price elasticity between two products. Parameter $k$ measures the effect of expenditure advertising on bundle sales. The larger the value of $k$, the more efficient the effort of advertising in encouraging customers to purchase (Yan et al. 2014).

In this model, the manufacturer can influence demand by setting the wholesale price for bundled products. On the other hand, the retailer can independently influence the selling price and advertising investment of each product. Each channel member in the supply chain expects to maximise his own profit, irrespective of the other. This leads to the following assumptions.

Assumption 5 All members in the supply chain try to maximise their profit as if they have perfect information on the demand and cost structure of the other member (Jena and Sarmah 2014; Yan et al. 2014).

Assumption 6 Here, it is assumed that the cost of advertising effort by the retailer is $\theta A^{2}$ (for both component products and bundling products).

Fixed payment $A$ is spent by the retailer for advertising, who sells the bundled product and component products in the market. The cost of advertising level has a decreasing-return 
property. The advertising effort is usually modelled as a function of the investment in the product (Tsay and Agrawal 2000; Yan et al. 2014). More effort by the retailer to sell bundle products from the market implies greater investment. Here, $\theta$ is a positive number. The parameter $\theta$ measures the effect of the invested advertising on bundling sales. The larger the value of $\theta$, the more efficient the invested advertising customer's purchases.

\subsection{Manufacturer bundling}

Under manufacturer bundling, the manufacturer produces a bundling product from the two component products, $a$ and $b$, and incurs the bundling $\cos t c_{B}$. Here, the manufacturer decides the wholesale prices and makes advertisements for selling their bundle product. In the second stage, the retailer takes the manufacturer's wholesale price of the bundle product and then unbundles the product, sets the retail price of each of the component's product ( $p_{a i}$ and $p_{b i}$ for manufacturer $i$ and $p_{a j}$ and $p_{b j}$ for manufacturer $\mathrm{j}$, respectively) and, finally, sells these component products into the products. Here, we assume that the retailer sells the products of manufacturer i and manufacturer $\mathrm{j}$ with a price $p_{i}\left(p_{a i}=p_{b i}=p_{i}\right)$ and $p_{j}\left(p_{a j}=p_{b j}=p_{j}\right)$, respectively. Here, it is assumed that the retailer tries to sell the component products with a lower price compared to bundling the product; and that the total selling price of these two component products is higher than the single bundling product. In this case the retailer makes an effort, when advertising, to sell their component products to the retailer. The objective functions of the manufacturer and retailer under a pure bundling strategy are given as follows.

$$
\begin{aligned}
\pi_{r}^{M}= & D_{B i}\left(2 p_{i}-w_{B i}\right)+D_{j}\left(2 p_{j}-w_{B j}\right)-\theta A^{2} \\
= & \left(\alpha_{n}-\beta_{n}\left(w_{B i}-m\right)+\gamma_{n}\left(w_{B j}-m\right)+k A\right)\left(w_{B i}-2 m\right) \\
& +\left(\alpha_{n}-\beta_{n}\left(w_{B j}-m\right)+\gamma_{n}\left(w_{B i}-m\right)+k A\right)\left(\left(w_{B j}-2 m\right)\right)-\theta A^{2}
\end{aligned} \quad(i, j=1,2, i \neq j)
$$

Subject to

$$
\begin{gathered}
p_{i} \leq w_{B i} \text { and } p_{j} \leq w_{B j} \\
2 p_{i}>w_{B i} \text { and } 2 p_{j}>w_{B j} \\
\pi_{s i}^{M}=\left(w_{B i}-c_{B}\right) D_{B i} \\
\pi_{s j}^{M}=\left(w_{B j}-c_{B}\right) D_{B j}
\end{gathered}
$$

\subsubsection{Manufacture-Stackelberg (MS)}

Under the assumption, MS, the manufacturer takes the retailer's reaction function into the consideration of their respective price decisions. Here, retailer reaction function, given a wholesale price $w_{B i}$ and $w_{B j}$, can be derived from the first-order condition of (3.1).

$$
\begin{gathered}
p_{i} \in \underset{p_{i}}{\arg \max } \pi_{r}^{M}\left(p_{i}, p_{j}, A \mid w_{B i}, w_{B j}\right) \\
A \in \underset{A}{\arg \max } \pi_{r}^{M}\left(p_{i}, p_{j}, A \mid w_{B i}, w_{B j}\right)
\end{gathered}
$$

where $i, j=1,2, i \neq j$. Since the objective function is concave in nature as $\frac{\partial^{2} \pi_{r}^{M}}{\partial m^{2}}=-8$ $\left(\beta_{n}-\gamma_{n}\right), \frac{\partial^{2} \pi_{r}^{M}}{\partial A^{2}}=-2 \theta$ and $\frac{\partial \pi_{r}^{M}}{\partial m \partial A}=-4 k$, it is solved by the first-order condition and the value of price and advertising effort are as follows:

$$
m=\frac{3}{8}\left(w_{B i}+w_{B j}\right)+\frac{A k+\alpha_{n}}{2\left(-\beta_{n}+\gamma_{n}\right)} \quad(i, j=1,2, i \neq j)
$$




$$
A=\frac{k\left(-2 m+w_{B i}\right)}{\theta} \quad(i, j=1,2, i \neq j)
$$

Solving $(3.6,3.7)$ simultaneously, one can determine the equilibrium value of $m *$ and $A *$ are as follows:

$$
\begin{gathered}
m^{*}=\frac{w_{B i}\left(4 k^{2}-3 \theta \beta_{n}+3 \theta \gamma_{n}\right)+\theta\left(4 \alpha_{n}+3 w_{B j}\left(-\beta_{n}+\gamma_{n}\right)\right)}{8\left(k^{2}-\theta \beta_{n}+\theta \gamma_{n}\right)} \\
A *=\frac{-k\left(4 \alpha_{n}+\left(w_{B i}-3 w_{B j}\right)\left(\beta_{n}-\gamma_{n}\right)\right)}{4\left(k^{2}-\theta \beta_{n}+\theta \gamma_{n}\right)}
\end{gathered}
$$

It can be seen that the equilibrium of retail margin, advertising and demand of bundle product are a linear function of wholesale price by the manufacturer.

$$
w_{B i} \in \underset{w_{B i}}{\arg \max } \pi_{m}^{M}\left(w_{B i}, w_{B j} \mid, p_{i}, p_{j}, A\right)
$$

Using the reaction function Eqs. (3.8-3.9), the manufacturers' equilibrium wholesale price can be derived following the first-order conditions of the respective manufacturers' profit maximisation problem (Eq. (3.2)].

$$
\frac{\partial}{\partial w_{B i}} \pi_{s}^{M}\left(m\left(w_{B i}\right), w_{B j}\right)=0,
$$

Solving (3.10) results in the following wholesale prices.

$$
w_{\mathrm{Bi}}=\frac{4 \theta \alpha_{n}\left(-\beta_{n}+\gamma_{n}\right)+c_{B}\left(\beta_{n}\left(6 k^{2}-5 \theta \beta_{n}\right)+2\left(k^{2}+\theta \beta_{n}\right) \gamma_{n}+3 \theta \gamma_{n}^{2}\right)}{-7 \theta \beta_{n}^{2}+6 \beta_{n}\left(k^{2}+\theta \gamma_{n}\right)+\gamma_{n}\left(2 k^{2}+\theta \gamma_{n}\right)}
$$

Likewise, we can discover the optimal value of $w_{\mathrm{Bj}}$ from the Eq. (3.3).

$$
w_{\mathrm{Bj}}=\frac{4 \theta \alpha_{n}\left(-\beta_{n}+\gamma_{n}\right)+c_{B}\left(\beta_{n}\left(6 k^{2}-5 \theta \beta_{n}\right)+2\left(k^{2}+\theta \beta_{n}\right) \gamma_{n}+3 \theta \gamma_{n}^{2}\right)}{-7 \theta \beta_{n}^{2}+6 \beta_{n}\left(k^{2}+\theta \gamma_{n}\right)+\gamma_{n}\left(2 k^{2}+\theta \gamma_{n}\right)}
$$

Solving Eqs. (3.8, 3.9, 3.12, and 3.13) simultaneously, the optimal solution of $w_{B i}^{*}, w_{B j}^{*}, A^{*}$, and $m^{*}$ can be determined. Finally, the demand quantise for manufacturer $i$ can be determined as:

$$
\begin{gathered}
w_{\mathrm{Bi}}^{*}=\frac{4 \theta \alpha_{n}\left(-\beta_{n}+\gamma_{n}\right)+c_{B}\left(\beta_{n}\left(6 k^{2}-5 \theta \beta_{n}\right)+2\left(k^{2}+\theta \beta_{n}\right) \gamma_{n}+3 \theta \gamma_{n}^{2}\right)}{-7 \theta \beta_{n}^{2}+6 \beta_{n}\left(k^{2}+\theta \gamma_{n}\right)+\gamma_{n}\left(2 k^{2}+\theta \gamma_{n}\right)} \\
w_{\mathrm{Bj}}^{*}=\frac{4 \theta \alpha_{n}\left(-\beta_{n}+\gamma_{n}\right)+c_{B}\left(\beta_{n}\left(6 k^{2}-5 \theta \beta_{n}\right)+2\left(k^{2}+\theta \beta_{n}\right) \gamma_{n}+3 \theta \gamma_{n}^{2}\right)}{-7 \theta \beta_{n}^{2}+6 \beta_{n}\left(k^{2}+\theta \gamma_{n}\right)+\gamma_{n}\left(2 k^{2}+\theta \gamma_{n}\right)} \\
p_{i}^{*}=\frac{3 c_{B}}{4}+\frac{-k^{2} c_{B}+2 \theta \alpha_{n}}{4\left(k^{2}-\theta \beta_{n}+\theta \gamma_{n}\right)}+\frac{4 \theta \beta_{n}\left(-2 \alpha_{n}+c_{B}\left(\beta_{n}-\gamma_{n}\right)\right)}{-7 \theta \beta_{n}^{2}+6 \beta_{n}\left(k^{2}+\theta \gamma_{n}\right)+\gamma_{n}\left(2 k^{2}+\theta \gamma_{n}\right)} \\
p_{j}^{*}==\frac{3 c_{B}}{4}+\frac{-k^{2} c_{B}+2 \theta \alpha_{n}}{4\left(k^{2}-\theta \beta_{n}+\theta \gamma_{n}\right)}+\frac{4 \theta \beta_{n}\left(-2 \alpha_{n}+c_{B}\left(\beta_{n}-\gamma_{n}\right)\right)}{-7 \theta \beta_{n}^{2}+6 \beta_{n}\left(k^{2}+\theta \gamma_{n}\right)+\gamma_{n}\left(2 k^{2}+\theta \gamma_{n}\right)} \\
A^{*}=\frac{k\left(-2 \alpha_{n}+c_{B}\left(\beta_{n}-\gamma_{n}\right)\right)\left(\beta_{n}\left(6 k^{2}-5 \theta \beta_{n}\right)+2\left(k^{2}+\theta \beta_{n}\right) \gamma_{n}+3 \theta \gamma_{n}^{2}\right)}{2\left(k^{2}-\theta \beta_{n}+\theta \gamma_{n}\right)\left(-7 \theta \beta_{n}^{2}+6 \beta_{n}\left(k^{2}+\theta \gamma_{n}\right)+\gamma_{n}\left(2 k^{2}+\theta \gamma_{n}\right)\right)}
\end{gathered}
$$

Considering Eqs. (3.14-3.18), the optimal demand function and total profit can be derived.

$$
\begin{gathered}
D_{i}=\left(\alpha_{\mathrm{Bi}}-\beta_{1} p_{\mathrm{Bi}}^{*}+\gamma p_{\mathrm{Bj}}^{*}+k A^{*}\right) \quad(i, j=1,2, i \neq j) \\
\pi_{T}^{M *}=\pi_{s i}^{M *}+\pi_{s j}^{M *}+\pi_{r}^{M *}
\end{gathered}
$$




\subsubsection{Retailer-Stackelberg (RS)}

Here, in RS, the retailer becomes the leader and manufacturers the followers. This scenario arises in the market, where retailers' size is large compared to their suppliers. For example, large retailers like Walmart and Costco can influence each product's sales by lowering the price. Because of their large market sizes, the retailers can sustain their margin on sales, while holding profit from their manufacturers. In this market, the retailer takes the manufacturers' reaction function into account for their own (retailer) price decisions. Here, the retailer problem is solved given that the retailer knows the manufacturers' reactions towards their retail price. From Eq. (3.20), the optimal wholesale price of manufacturer $i$ is defined as follows.

$$
w_{B i} \underset{w_{B i}}{\operatorname{argmax}} \pi_{s}^{M}\left(w_{B i}, w_{B j} \mid, p_{i}, p_{j}, A\right)
$$

where $i, j=1,2, i \neq j$. Since the objective function is concave in nature as $\frac{\partial^{2} \pi_{m}^{M}}{\partial w_{B i}^{2}}=-2 \beta_{n}$, it is solved by the first-order condition and the value of wholesale price is as follows:

$$
0=\frac{\partial \pi_{m}^{M}}{\partial w_{B i}}=A k+\alpha_{n}-\left(-m+w_{B i}\right) \beta_{n}-\left(-c_{B}+w_{B i}\right) \beta_{n}+\left(-m+w_{B j}\right) \gamma_{n}
$$

We can discover the optimal value pf the wholesale price is as follows:

$$
w_{B i}=\frac{A k+\alpha_{n}+\left(m+c_{B}\right) \beta_{n}-m \gamma_{n}}{2 \beta_{n}-\gamma_{n}}, \quad(i, j=1,2, i \neq j)
$$

Similarly, we can discover manufacturer 2 .

$$
w_{B j}=\frac{A k+\alpha_{n}+\left(m+c_{B}\right) \beta_{n}-m \gamma_{n}}{2 \beta_{n}-\gamma_{n}} \quad(i, j=1,2, i \neq j)
$$

Using the reaction function (Eqs. 3.22 and 3.23), the retailer's equilibrium retail price can be derived from the following first-order conditions of the respective retailer's profit maximisation problem in (Eq. 3.24).

$$
\begin{gathered}
p_{i} \in \underset{p_{i}}{\arg \max } \pi_{r}^{M}\left(p_{i}, p_{j}, A \mid w_{B i}, w_{B j}\right) \\
\frac{\partial}{\partial A} \pi_{r}^{M}\left(w_{B i}\left(p_{i}\right), p_{j}\right)=0, \\
A=\frac{k \beta_{n}\left(-2 \alpha_{n}+2 m \beta_{n}-c_{B} \gamma_{n}\right)}{-4 \theta \beta_{n}^{2}-\theta \gamma_{n}^{2}+2 \beta_{n}\left(k^{2}+2 \theta \gamma_{n}\right)} \\
\frac{\partial}{\partial m} \pi_{r}^{M}\left(w_{B i}\left(p_{i}(m)\right), p_{j}(m)\right)=0, \\
m=\frac{1}{2}\left(c_{B}+\frac{A k+\alpha_{n}+c_{B} \beta_{n}}{3 \beta_{n}-\gamma_{n}}+\frac{A k+\alpha_{n}}{-\beta_{n}+\gamma_{n}}\right)
\end{gathered}
$$

Solving Eqs. 3.22, 3.23, 3.26, and 3.28, the optimal solution of $p_{B i} *, p_{B j} *, w_{B i} *, w_{B j} *$ and $\mathrm{A}^{*}$ can be determined. Finally, the demand quantise for manufacturer $i$ can be determined as:

$$
\begin{aligned}
p_{B i}^{*} & =\frac{2 \theta \alpha_{n}\left(-2 \beta_{n}+\gamma_{n}\right)+c_{B} \beta_{n}\left(2 k^{2}-\theta \beta_{n}+\theta \gamma_{n}\right)}{-6 \theta \beta_{n}^{2}-2 \theta \gamma_{n}^{2}+4 \beta_{n}\left(k^{2}+2 \theta \gamma_{n}\right)} \\
p_{B j}^{*}= & \frac{2 \theta \alpha_{n}\left(-2 \beta_{n}+\gamma_{n}\right)+c_{B} \beta_{n}\left(2 k^{2}-\theta \beta_{n}+\theta \gamma_{n}\right)}{-6 \theta \beta_{n}^{2}-2 \theta \gamma_{n}^{2}+4 \beta_{n}\left(k^{2}+2 \theta \gamma_{n}\right)}
\end{aligned}
$$




$$
\begin{gathered}
w_{B i}^{*}=\frac{2 \theta \alpha_{n}\left(-\beta_{n}+\gamma_{n}\right)+c_{B}\left(-5 \theta \beta_{n}^{2}-\theta \gamma_{n}^{2}+\beta_{n}\left(4 k^{2}+6 \theta \gamma_{n}\right)\right)}{-6 \theta \beta_{n}^{2}-2 \theta \gamma_{n}^{2}+4 \beta_{n}\left(k^{2}+2 \theta \gamma_{n}\right)} \\
w_{B j}^{*}=\frac{2 \theta \alpha_{n}\left(-\beta_{n}+\gamma_{n}\right)+c_{B}\left(-5 \theta \beta_{n}^{2}-\theta \gamma_{n}^{2}+\beta_{n}\left(4 k^{2}+6 \theta \gamma_{n}\right)\right)}{-6 \theta \beta_{n}^{2}-2 \theta \gamma_{n}^{2}+4 \beta_{n}\left(k^{2}+2 \theta \gamma_{n}\right)} \\
A^{*}=\frac{k \beta_{n}\left(-2 \alpha_{n}+c_{B}\left(\beta_{n}-\gamma_{n}\right)\right)}{-3 \theta \beta_{n}^{2}-\theta \gamma_{n}^{2}+2 \beta_{n}\left(k^{2}+2 \theta \gamma_{n}\right)}
\end{gathered}
$$

Considering Eqs. (3.29-3.33), we can derive the optimal value of demand and total profit is as follows: $D_{i}=\left(\alpha_{B i}-\beta_{1} p_{B i}^{*}+\gamma p_{B j}^{*}+k A^{*}\right)$, where $i, j=1,2, i \neq j$.

$$
\pi_{T}^{M *}=\pi_{s i}^{M *}+\pi_{s j}^{M *}+\pi_{r}^{M *}
$$

\subsubsection{Vertical Nash (VN)}

The Vertical Nash (VN) model is studied as a benchmark to both the Manufacturer Stackelberg and Retailer Stackelberg cases. Here, each manufacturer has equal bargaining power and, thus, makes decisions simultaneously. This scenario arises in small to medium-sized manufacturers and retailers (Lu et al. 2011). In this case, a manufacturer does not dominate over the retailer. Thus, the manufacturer's wholesale price decisions depend on the retailer's selling price. Meanwhile, retailer price decisions are dependent on the wholesale price. The reaction functions of the retailer and manufacturer are derived in MS and RS respectively. From MS, the manufacturer reaction functions of $m$ and $A$ are given in Eqs. (3.8) and (3.9), respectively while, in RS, the manufacturer's reaction functions for $w_{B i}$ and $w_{B i}$ are given in Eqs. (3.22) and (3.23), respectively. The optimal selling price, wholesale price and advertising level can be derived by solving all these equations simultaneously.

$$
\begin{gathered}
w_{\mathrm{Bi}}^{*}=\frac{2 \theta \alpha_{n}\left(-\beta_{n}+\gamma_{n}\right)+4 c_{B} \beta_{n}\left(k^{2}-\theta \beta_{n}+\theta \gamma_{n}\right)}{-5 \theta \beta_{n}^{2}-\theta \gamma_{n}^{2}+\beta_{n}\left(4 k^{2}+6 \theta \gamma_{n}\right)} \\
w_{\mathrm{Bj}}^{*}=\frac{2 \theta \alpha_{n}\left(-\beta_{n}+\gamma_{n}\right)+4 c_{B} \beta_{n}\left(k^{2}-\theta \beta_{n}+\theta \gamma_{n}\right)}{-5 \theta \beta_{n}^{2}-\theta \gamma_{n}^{2}+\beta_{n}\left(4 k^{2}+6 \theta \gamma_{n}\right)} \\
A^{*}=-\frac{2 k \beta_{n}\left(2 \alpha_{n}+c_{B}\left(-\beta_{n}+\gamma_{n}\right)\right)}{-5 \theta \beta_{n}^{2}-\theta \gamma_{n}^{2}+\beta_{n}\left(4 k^{2}+6 \theta \gamma_{n}\right)} \\
p_{i}^{*}=\frac{\theta \alpha_{n}\left(-3 \beta_{n}+\gamma_{n}\right)+c_{B} \beta_{n}\left(2 k^{2}-\theta \beta_{n}+\theta \gamma_{n}\right)}{-5 \theta \beta_{n}^{2}-\theta \gamma_{n}^{2}+\beta_{n}\left(4 k^{2}+6 \theta \gamma_{n}\right)} \quad(i, j=1,2, i \neq j)
\end{gathered}
$$

Considering Eqs. (3.35) to Eqs. (3.38), the optimal demand function and total profit can be derived.

$$
\begin{gathered}
D_{i}=\left(\alpha_{\mathrm{Bi}}-\beta_{1} p_{\mathrm{Bi}}^{*}+\gamma p_{\mathrm{Bj}}^{*}+k A^{*}\right) \quad(i, j=1,2, i \neq j) \\
\pi_{T}^{M *}=\pi_{s i}^{M *}+\pi_{s j}^{M *}+\pi_{r}^{M *}
\end{gathered}
$$

\subsection{Retailer bundling}

Under retail bundling, it is considered that the manufacturer produces only two component products, while the retailer produces the bundle from the component products and incurs the unit bundling cost $c_{B}$. Here, it is considered that the wholesale price of two components ( $a$ and $\mathrm{b}$ ) are the same $w_{a i}=w_{b i}=w_{i}$ for a manufacturer.

$$
\pi_{r}^{R}=D_{B i}\left(p_{B i}-2 w_{i}-c_{B}\right)+D_{B j}\left(p_{B j}-2 w_{j}-c_{B}\right)-\theta A^{2}, \quad(i, j=1,2, i \neq j)
$$




$$
\begin{aligned}
& \pi_{s i}^{R}=2\left(w_{i}\right) D_{B i} \quad(i, j=1,2, i \neq j) \\
& \pi_{s j}^{R}=2\left(w_{j}\right) D_{B j} \quad(i, j=1,2, i \neq j)
\end{aligned}
$$

\subsubsection{Manufacture-Stackelberg (MS)}

Under the assumption of MS, the manufacturer takes the retailer's reaction function into the consideration of their respective price decisions. Here, retailer reaction function, given wholesale price $w_{i}$ and $w_{j}$ can be derived from the first-order condition of Eqs. (3.43)-(3.44):

$$
\begin{gathered}
p_{B i} \in \underset{p_{B i}}{\arg \max } \pi_{r}^{R}\left(p_{B i}, p_{B j}, A \mid w_{i}, w_{j}\right) \\
A \in \underset{A}{\arg \max } \pi_{r}^{R}\left(p_{B i}, p_{B j}, A \mid w_{i}, w_{j}\right)
\end{gathered}
$$

where $i, j=1,2, i \neq j$. Since the objective function is concave in nature as $\frac{\partial^{2} \pi_{r}^{R}}{\partial m^{2}}=-4 \beta_{n}+4 \gamma_{n}$, $\frac{\partial^{2} \pi_{r}^{R}}{\partial A^{2}}=-2 \theta$ and $\frac{\partial \pi_{r}^{R}}{\partial p_{B i} \partial A}=2 k$, it is solved by first-order condition and the value of retail margin and advertising effort are as follows:

$$
\begin{gathered}
\frac{\partial \pi_{r}^{R}}{\partial m}=0 \\
m=\frac{1}{2}\left(c_{B}-w_{i}-w_{j}+\frac{A k+\alpha_{n}}{\beta_{n}-\gamma_{n}}\right) \\
\quad \frac{\partial \pi_{r}^{R}}{\partial A}=-2 A \theta+2 k\left(m-c_{B}\right) \\
A=\frac{k\left(m-c_{B}\right)}{\theta} \quad(i, j=1,2, i \neq j)
\end{gathered}
$$

Solving Eqs. (3.45) and (3.47) simultaneously, the equilibrium value of $m^{*}$ and $A *$ can be determined as follows:

$$
\begin{gathered}
A *=\frac{k\left(-\alpha_{n}+\left(c_{B}+w_{i}+w_{j}\right)\left(\beta_{n}-\gamma_{n}\right)\right)}{k^{2}-2 \theta \beta_{n}+2 \theta \gamma_{n}}, \quad(i, j=1,2, i \neq j) \\
m *=\frac{-\theta \alpha_{n}+\theta\left(w_{i}+w_{j}\right)\left(\beta_{n}-\gamma_{n}\right)+c_{B}\left(k^{2}-\theta \beta_{n}+\theta \gamma_{n}\right)}{k^{2}-2 \theta \beta_{n}+2 \theta \gamma_{n}}, \quad(i, j=1,2, i \neq j),
\end{gathered}
$$

It can be seen that the equilibrium price, advertising and demand of bundle product are linear functions of the wholesale price by the manufacturer. Using the reaction function (3.48-3.49), the manufacturers' equilibrium wholesale price can be derived from the following first-order conditions of the respective manufacturers' profit maximisation problem:

$$
\begin{gathered}
w_{i} \in \underset{w_{i}}{\arg \max } \pi_{m}^{R}\left(w_{i}, w_{j} \mid, p_{B i}, p_{B j}, A\right) \quad(i, j=1,2, i \neq j) \\
\frac{\partial}{\partial w_{i}} \pi_{m}^{R}\left(p_{B i}\left(w_{i}\right), w_{j}\right)=0, \quad(i, j=1,2, i \neq j)
\end{gathered}
$$

Solving (3.50) results in the following wholesale prices:

$$
w_{i}=\frac{-\theta\left(\beta_{n}-\gamma_{n}\right)\left(\alpha_{n}+c_{B}\left(-\beta_{n}+\gamma_{n}\right)\right)+w_{j}\left(-\theta \beta_{n}^{2}+\beta_{n}\left(k^{2}-2 \theta \gamma_{n}\right)+\gamma_{n}\left(k^{2}+3 \theta \gamma_{n}\right)\right)}{2\left(-3 \theta \beta_{n}^{2}+\gamma_{n}\left(k^{2}+\theta \gamma_{n}\right)+\beta_{n}\left(k^{2}+2 \theta \gamma_{n}\right)\right)}
$$


Similarly, the wholesale price that can be obtained for manufacturer 2 is derived as follows:

$$
w_{j}=\frac{-\theta\left(\beta_{n}-\gamma_{n}\right)\left(\alpha_{n}+c_{B}\left(-\beta_{n}+\gamma_{n}\right)\right)+w_{i}\left(-\theta \beta_{n}^{2}+\beta_{n}\left(k^{2}-2 \theta \gamma_{n}\right)+\gamma_{n}\left(k^{2}+3 \theta \gamma_{n}\right)\right)}{2\left(-3 \theta \beta_{n}^{2}+\gamma_{n}\left(k^{2}+\theta \gamma_{n}\right)+\beta_{n}\left(k^{2}+2 \theta \gamma_{n}\right)\right)}
$$

Solving Eqs. (3.48, 3.49, 3.52, and 3.53), the optimal solution of $p_{B i} *, p_{B j} *$ and $A^{*}$ can be determined.

$$
\begin{gathered}
w_{i}^{*}=\frac{\theta\left(\beta_{n}-\gamma_{n}\right)\left(\alpha_{n}+c_{B}\left(-\beta_{n}+\gamma_{n}\right)\right)}{5 \theta \beta_{n}^{2}+\gamma_{n}\left(-k^{2}+\theta \gamma_{n}\right)-\beta_{n}\left(k^{2}+6 \theta \gamma_{n}\right)} \\
w_{j}^{*}=\frac{\theta\left(\beta_{n}-\gamma_{n}\right)\left(\alpha_{n}+c_{B}\left(-\beta_{n}+\gamma_{n}\right)\right)}{5 \theta \beta_{n}^{2}+\gamma_{n}\left(-k^{2}+\theta \gamma_{n}\right)-\beta_{n}\left(k^{2}+6 \theta \gamma_{n}\right)} \\
A^{*}=\frac{-k\left(\alpha_{n}+c_{B}\left(-\beta_{n}+\gamma_{n}\right)\right)\left(-3 \theta \beta_{n}^{2}+\gamma_{n}\left(k^{2}+\theta \gamma_{n}\right)+\beta_{n}\left(k^{2}+2 \theta \gamma_{n}\right)\right)}{\left(k^{2}-2 \theta \beta_{n}+2 \theta \gamma_{n}\right)\left(-5 \theta \beta_{n}^{2}+\gamma_{n}\left(k^{2}-\theta \gamma_{n}\right)+\beta_{n}\left(k^{2}+6 \theta \gamma_{n}\right)\right)} \\
p_{\mathrm{Bi}}^{*}=\frac{1}{6}\left(-3 c_{B}+\frac{k^{2} c_{B}-2 \theta \alpha_{n}}{k^{2}-2 \theta \beta_{n}+2 \theta \gamma_{n}}+\frac{8 \theta \alpha_{n}\left(-2 \beta_{n}+\gamma_{n}\right)+8 c_{B}\left(\beta_{n}\left(k^{2}-3 \theta \beta_{n}\right)+\left(k^{2}+3 \theta \beta_{n}\right) \gamma_{n}\right)}{-5 \theta \beta_{n}^{2}+\gamma_{n}\left(k^{2}-\theta \gamma_{n}\right)+\beta_{n}\left(k^{2}+6 \theta \gamma_{n}\right)}\right) \\
p_{\mathrm{Bj}}^{*}=\frac{1}{6}\left(-3 c_{B}+\frac{k^{2} c_{B}-2 \theta \alpha_{n}}{k^{2}-2 \theta \beta_{n}+2 \theta \gamma_{n}}+\frac{8 \theta \alpha_{n}\left(-2 \beta_{n}+\gamma_{n}\right)+8 c_{B}\left(\beta_{n}\left(k^{2}-3 \theta \beta_{n}\right)+\left(k^{2}+3 \theta \beta_{n}\right) \gamma_{n}\right)}{-5 \theta \beta_{n}^{2}+\gamma_{n}\left(k^{2}-\theta \gamma_{n}\right)+\beta_{n}\left(k^{2}+6 \theta \gamma_{n}\right)}\right)
\end{gathered}
$$

Finally, the demand quantise for manufacturer $i$ can be determined as:

$$
D_{i}=\left(\alpha_{\mathrm{Bi}}-\beta_{1} p_{\mathrm{Bi}}^{*}+\gamma p_{\mathrm{Bj}}^{*}+k A^{*}\right)
$$

where $i, j=1,2, i \neq j$.

$$
\pi_{T}^{M *}=\pi_{s i}^{M *}+\pi_{s j}^{M *}+\pi_{r}^{M *}
$$

\subsubsection{Retailer-Stackelberg (RS)}

In this model, the retailer becomes the leader and manufacturers the followers. Here, the retailer takes the manufacturers' reaction function into account for its own retailer price decision. Thus, the retailer problem is solved given that the retailer knows the manufacturers' reactions towards their retail price.

$$
\begin{gathered}
w_{i} \in \underset{w_{i}}{\operatorname{argmax}} \pi_{s}^{R}\left(w_{i}, w_{j} \mid, p_{B i}, p_{B j}, A\right) \\
0=\frac{\partial \pi_{m}^{R}}{\partial w_{i}}=-4 w_{i} \beta_{n}+2\left(A k+\alpha_{n}-\left(m+2 w_{i}\right) \beta_{n}+\left(m+2 w_{j}\right) \gamma_{n}\right)
\end{gathered}
$$

From Eq. (3.60), the optimal wholesale price of manufacturer $i$ is defined as follows.

Where $i, j=1,2, i \neq j$. Since the manufacturer's profit is concave in $w_{i}$, as $\frac{\partial^{2} \pi_{m}^{R}}{\partial w_{i}^{2}}=-8 \beta_{n}<$ 0 . Then, from the first order derivation, the optimal wholesale price of component products is obtained as:

$$
w_{i}=\frac{A k+\alpha_{n}-m \beta_{n}+\left(m+2 w_{j}\right) \gamma_{n}}{4 \beta_{n}},
$$

Likewise, we can obtain the wholesale price for manufacturer 2 is determined as follows:

$$
w_{j}=\frac{A k+\alpha_{n}-m \beta_{n}+\left(m+2 w_{j}\right) \gamma_{n}}{4 \beta_{n}},
$$


Using the reaction function (3.51 and 3.52), the retailer' equilibrium retail price can be derived from the following first-order conditions of the respective retailer's profit maximisation problem Eqs. (3.64-3.65).

$$
\begin{gathered}
p_{B i} \in \underset{p_{B i}}{\arg \max } \pi_{r}^{R}\left(p_{B i}, p_{B j}, A \mid w_{i}, w_{j}\right) \\
A \in \underset{A}{\arg \max } \pi_{r}^{R}\left(p_{B i}, p_{B j}, A \mid w_{i}, w_{j}\right) \\
\frac{\partial}{\partial p_{B i}} \pi_{r}^{R}\left(w_{i}\left(p_{B i}\right), p_{B j}\right)=0 \\
\frac{\partial}{\partial A} \pi_{r}^{R}\left(w_{i}\left(p_{B i}\right), p_{B j}\right)=0
\end{gathered}
$$

Solving (3.66 and 3.67) results in the following retailer margin and advertising levels are as follows:

$$
\begin{gathered}
m=\frac{1}{2}\left(c_{B}+\frac{A k+\alpha_{n}}{\beta_{n}-\gamma_{n}}\right), \quad(i, j=1,2, i \neq j) \\
A=\frac{-k\left(\gamma\left(p_{B i}+p_{B j}\right)+\alpha_{B i}+\alpha_{B j}\right)+k\left(-c_{B}+p_{B i}+p_{B j}\right) \beta_{1}}{2 k^{2}+\theta \beta_{1}} \quad(i, j=1,2, i \neq j)
\end{gathered}
$$

Solving Eqs. (3.62, 3.63, 3.68, and 3.69), the optimal solution of $p_{B i} *, p_{B j} *, w_{B i} *, w_{B j} *$ and $A *$ can be determined. Finally, the demand quantise for manufacturer $i$ can be determined as:

$$
\begin{gathered}
p_{\mathrm{Bi}}^{*}=\frac{\theta \alpha_{n}\left(-3 \beta_{n}+2 \gamma_{n}\right)+c_{B} \beta_{n}\left(k^{2}-\theta \beta_{n}+\theta \gamma_{n}\right)}{-4 \theta \beta_{n}^{2}-2 \theta \gamma_{n}^{2}+\beta_{n}\left(k^{2}+6 \theta \gamma_{n}\right)} \\
p_{\mathrm{Bj}}^{*}=\frac{\theta \alpha_{n}\left(-3 \beta_{n}+2 \gamma_{n}\right)+c_{B} \beta_{n}\left(k^{2}-\theta \beta_{n}+\theta \gamma_{n}\right)}{-4 \theta \beta_{n}^{2}-2 \theta \gamma_{n}^{2}+\beta_{n}\left(k^{2}+6 \theta \gamma_{n}\right)} \\
w_{i}^{*}=\frac{-\theta \alpha_{n} \beta_{n}+\theta c_{B} \beta_{n}^{2}+\theta \alpha_{n} \gamma_{n}-2 \theta c_{B} \beta_{n} \gamma_{n}+\theta c_{B} \gamma_{n}^{2}}{-2\left(-k^{2} \beta_{n}+4 \theta \beta_{n}^{2}-6 \theta \beta_{n} \gamma_{n}+2 \theta \gamma_{n}^{2}\right)} \\
w_{j}^{*}=\frac{-\theta \alpha_{n} \beta_{n}+\theta c_{B} \beta_{n}^{2}+\theta \alpha_{n} \gamma_{n}-2 \theta c_{B} \beta_{n} \gamma_{n}+\theta c_{B} \gamma_{n}^{2}}{-2\left(-k^{2} \beta_{n}+4 \theta \beta_{n}^{2}-6 \theta \beta_{n} \gamma_{n}+2 \theta \gamma_{n}^{2}\right)}
\end{gathered}
$$

Then we can obtain the optimal value of demand.

$$
D_{i}=\left(\alpha_{\mathrm{Bi}}-\beta_{1} p_{\mathrm{Bi}}^{*}+\gamma p_{\mathrm{Bj}}^{*}+k A^{*}\right)
$$

where $i, j=1,2, i \neq j$.

Proposition 1 Under manufacturer and retailer bundling, the wholesale price increases with advertising elasticity in the RS power structure.

Proposition 1 states that the wholesale price of bundling products increases with advertising elasticity under the Retailer Stackelberg structure. It is observed that the retailer will sell the bundling product at a higher selling price and spend more on advertising for generating additional demand due to the high wholesale price. Refer to "Appendix 1" for more information. 
Proposition 2 Under manufacturer bundling, the retail margin of bundling products with the cost of advertising decreases in the MS power case, while it increases in the same proportions under retailer bundling.

Proposition 2 states that the retailer margin of bundled products increases by half when their proportion of advertisement costs increases under retailer bundling. The retailer sells bundling products with a higher selling price compared to that of the manufacturer, without bundling, due to their expenditure on advertising and bundling the product. Besides, the retailer wants to spend as much as possible on advertising costs to generate higher revenue (Hong et al. 2015). Refer to "Appendix 1" for more information.

\subsubsection{Vertical Nash (VN)}

The Vertical Nash model is studied as a benchmark to both the Manufacturer Stackelberg and Retailer Stackelberg cases. From MS, the manufacturer reaction functions of $m$ and $A$ are given in Eqs. (3.48) and (3.49), respectively while, in RS, the manufacturer's reaction functions for $w_{\mathrm{Bi}}$ and $w_{\mathrm{Bi}}$ are given in Eqs. (3.61) and (3.62) respectively. The optimal selling price, wholesale price and advertising level can be derived by solving all these equations simultaneously.

$$
\begin{aligned}
& p_{B i}^{*}= \frac{\theta \alpha_{n}\left(-2 \beta_{n}+\gamma_{n}\right)+c_{B} \beta_{n}\left(k^{2}-\theta \beta_{n}+\theta \gamma_{n}\right)}{-3 \theta \beta_{n}^{2}-\theta \gamma_{n}^{2}+\beta_{n}\left(k^{2}+4 \theta \gamma_{n}\right)} \\
& A^{*}=\frac{-k \beta_{n}\left(\alpha_{n}+c_{B}\left(-\beta_{n}+\gamma_{n}\right)\right)}{-3 \theta \beta_{n}^{2}-\theta \gamma_{n}^{2}+\beta_{n}\left(k^{2}+4 \theta \gamma_{n}\right)} \\
& p_{B j}^{*}=\frac{\theta \alpha_{n}\left(-2 \beta_{n}+\gamma_{n}\right)+c_{B} \beta_{n}\left(k^{2}-\theta \beta_{n}+\theta \gamma_{n}\right)}{-3 \theta \beta_{n}^{2}-\theta \gamma_{n}^{2}+\beta_{n}\left(k^{2}+4 \theta \gamma_{n}\right)}
\end{aligned}
$$

\section{Comparison of results}

The comparison of three different decision models under manufacturer bundling and retailer bundling are presented below. The reason for restricting the two manufacturers to having the same parametric values is to make the comparison of the three decision cases under two bundling models, where the asymmetry between the manufacturers creates problems in making a comparison in the three models. A comparison between all three decision models under manufacturer bundling and retailer bundling models is made.

Observation 1 The ordinal relationship between the optimal selling price and advertising level under manufacturing bundling and retailer bundling are as follows: $p_{B}^{M S R} \geq$ $w_{B}^{M S M}, p_{B}^{R S R}>w_{B}^{R S M}$ and $w_{B}^{V N M}<p_{B}^{V N R}$. Whereas $A^{M S M}>A^{M S R}, A^{R S M}>$ $A^{R S R}$, and $A^{V N M}>A^{V N R}$.

From Observation 1, it is observed that the equilibrium bundling retail prices are almost indistinguishable between manufacturing bundling and retailer bundling under all three cases. However, the bundling price is higher in retailer bundling compared to manufacturer bundling under the RS and VN cases. Here, the manufacturer sets the lower wholesale price of component products and the retailer produces the bundling product from the component products and sells those bundled products with a higher margin in VN and RS, as compared to MS, to generate higher profit, thereby increasing overall profit from the bundled products. The 
equilibrium bundling advertising effort level is almost indistinguishable between manufacturing bundling and retailer bundling under all three MS, RS and VN cases. Meanwhile, the advertising effort is higher in manufacturer bundling compared to retailer bundling under all three MS, RS and VN cases which means that the retailer makes more of an effort to sell component products compared to bundle products. Thereby, the demand in manufacturer bundling is higher when compared to that of retailer bundling. As a result, it attracts more customers to purchase bundled products. The results show that firms select manufacturer bundling compared to retailer bundling, while considering MS, RS and VN strategy for their business.

Observation 2 The ordinal relationship between the optimal selling price and advertising level under manufacturing bundling and retailer bundling are as follows: $p_{B}^{V N R} \leq p_{B}^{M S R} \leq$ $p_{B}^{R S R}$, and $w_{B}^{R S M} \leq w_{B}^{V N M} \leq w_{B}^{M S M}$, Whereas $A^{R S M}<A^{M S M} \leq A^{V N M}$ and $A^{R S R} \leq$ $A^{M S R} \leq A^{V N R}$

From Observation 2, it is observed that the equilibrium bundling retail prices, wholesale price and advertising effort are almost indistinguishable between MS, RS, and VN under both retailer bundling and manufacturer bundling strategies. Here, the manufacturer sets the lower wholesale price in VN and RS as compared to MS, in order to increase demand; thereby increasing the saving from bundled products. The retail price is mainly affected by wholesale price and a fraction of the collection rate. The demand in manufacturer bundling is higher, as compared to that of other models, because the advertising effort is higher in the VN case compared to other cases. As a result, it attracts more price sensitivity for the customer, when purchasing bundled products; furthermore, revenue attributed to the coordination can be effectively shared among supply chain members to increase supply, demand and profits.

\section{Numerical example}

In this subsection, a numerical study is conducted to illustrate the usefulness of developed models and test associated results. Hypothetical but relevant data are used for the numerical example, as obtaining real-time data on multi-attribute variables identified in the model was difficult. This approach is acceptable within academic research, where the possibility of collecting appropriate data for complex quantitative models is very difficult (e.g., Ma and Mallik 2017; Xu et al. 2018). Also, for the model's simplicity and to better visualise the behaviour of the proposed model, a sensitivity analysis of the model is conducted. The following parameter values are considered for illustrating the developed models: $\alpha_{\mathrm{n}}=120, \beta_{n}=40, \theta=.8, \gamma_{n}=30, c_{B}=10, \mathrm{c} 1=\mathrm{c} 2=0, k=.6$.

The results presented in Table 2 show that the channel profit is higher in manufacturer bundling compared to retailer bundling under price competition. Similar to Ma and Mallik (2017), manufacturer bundling makes a profit compared to retailer bundling under monopolistic situations. Although they did not consider price competition in their models, it is found that in manufacturer bundling, the individual component retail price is comparatively lower than the bundling price. Furthermore, the selling price of the bundling product in retailer bundling is higher compared to manufacturer bundling. However, the manufacturer makes less profit in retailer bundling compared to manufacturer bundling. The lower advertising effort and bundling cost negatively influences the manufacturer's profit. The advertising effort cost is higher in manufacturer bundling compared to retailer bundling which means that the retailer puts more effort into advertisements for component products to sell into the 
Table 2 Results by different bundling case

\begin{tabular}{|c|c|c|c|c|c|c|}
\hline \multirow[t]{2}{*}{ Parameter } & \multicolumn{3}{|c|}{ Manufacturer bundling } & \multicolumn{3}{|c|}{ Retailer bundling } \\
\hline & MS & RS & $\mathrm{VN}$ & MS & RS & VN \\
\hline$w_{B}$ & 10.94 & 10.81 & 10.86 & - & - & - \\
\hline$p$ & 8.89 & 9.05 & 8.86 & & - & - \\
\hline$p_{\mathrm{B}}$ & - & - & - & 11.14 & 11.22 & 11.13 \\
\hline A & 5.12 & 4.86 & 5.15 & 0.67 & 0.61 & 0.68 \\
\hline$\pi_{s i}$ & 32.13 & 26.16 & 29.57 & 2.00 & 1.67 & 2.02 \\
\hline$\pi_{s j}$ & 32.13 & 26.16 & 29.57 & 2.00 & 1.67 & 2.02 \\
\hline$\pi_{r}$ & 446.36 & 453.56 & 451.99 & 16.20 & 16.29 & 16.20 \\
\hline$\pi_{T}$ & 510.62 & 505.88 & 511.13 & 20.2 & 19.63 & 20.24 \\
\hline
\end{tabular}

market compared to bundled products. As a result, the demand of component products is increased compared to bundling products. Our result provides similar insights to those of Yan et al. (2014), that firms should invest less in advertising to promote bundled products during retailer bundling strategies.

This study shows that $V N$ provides higher profit compared to the other two $R S$ and $M S$ strategies under both bundling models. This happens as a result of lower retailing price and higher advertising effort. Consequently, demand for the product in VN is comparably higher than the MS and RS strategies. Thus, it might create an opportunity for the manufacturer and retailer to negotiate and delegate bundling decisions and to share profit in a supply chain network. Further, it is observed that the total profit in model MS is higher compared to model RS. This happens because of lower retail price and higher advertising effort. The equilibrium outcomes under retailer bundling and manufacturer bundling are different for RS models, whereas total profits in the MS and VN models are observed to be nearly equal for retailer and manufacturer bundling. Under retailer bundling, the retailer utilises limited capacity and spends less on advertising effort to produce more bundled products. Conversely, under manufacturer bundling, the manufacturer utilises limited capacity to produce less bundled products because bundling cost influences profit significantly when compared with component products.

\subsection{Sensitivity analysis and managerial insights}

A sensitivity analysis was carried out to examine the impact of various parameters on the model.

\subsubsection{Impact of market size}

The impact of market size, $\alpha_{n}$ on the total chain profit was studied, observing that the total chain profit increases exponentially, as the market size increases for all three cases of bundling (see Fig. 1a, b). When market size increases, the total profit for manufacturer bundling increases compared to that of the retailer. This happens because the retailer sells component products to the market with a higher retail price and also makes higher advertisement effort in $\mathrm{MB}$ compared to RB. The demand for bundling products in VN under RB and MB increases as the market size increases; therefore, generating more revenue for $\mathrm{VN}$ compared to the 


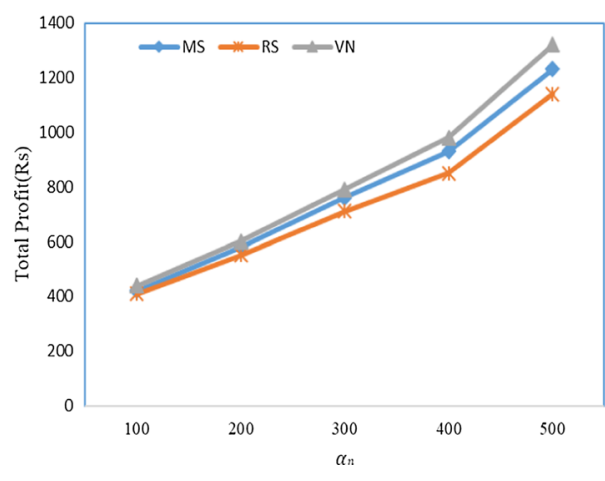

(a) Total profit for MB with different power cases different values of market size $(\alpha)$.

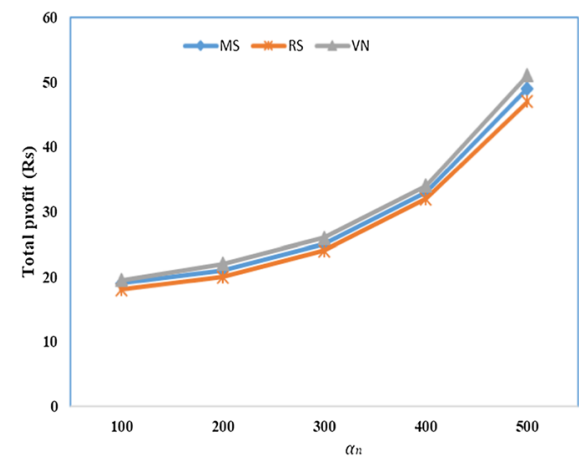

(b) Total profit for RB with different power cases different values of market size $(\alpha)$.

Fig. 1 a Total profit for MB with different power cases. $\mathbf{b}$ Total profit for RB with different power cases different values of market size $(\alpha)$. different values of market size $(\alpha)$

other cases. The manufacturer profit and retailer profit in VN is higher compared to the other two RS and MS strategies because of equal bargaining power between retailer and manufacturer. Again, it is observed that the total chain profit in MS under both manufacturer bundling and retailer bundling cases are equal as market size increases. Furthermore, both retailer and manufacturer can explore the demand in RS compared to the other two models under manufacturer bundling because of the better service offered by them to the customers.

\subsubsection{Impact of price elasticity}

The paper studied the impact of price elasticity, $\beta_{n}$ on the total chain profit for three cases under manufacturer and retailer bundling. The results presented in Fig. $2 a, b$ show that the total profit decreases exponentially as the value of price elasticity increases in retail and manufacturer bundling. When $\beta_{n}$ increases, the VN efforts result in higher profit compared with that in the RS and MS cases under bundling; this is because the retail margin of the respective products is higher compared to the other two cases. It is also observed that the

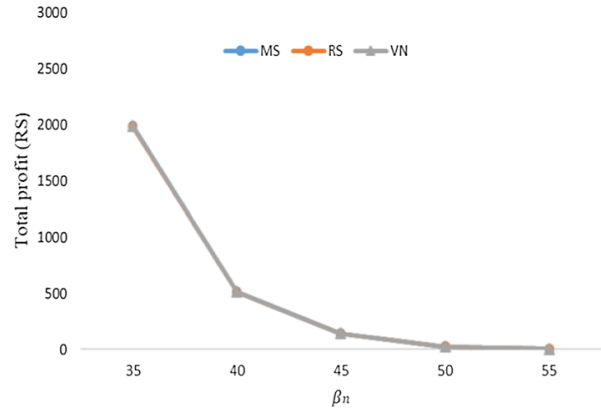

(a) Total profit for MB with different power cases different value of price elasticity $(\beta)$.

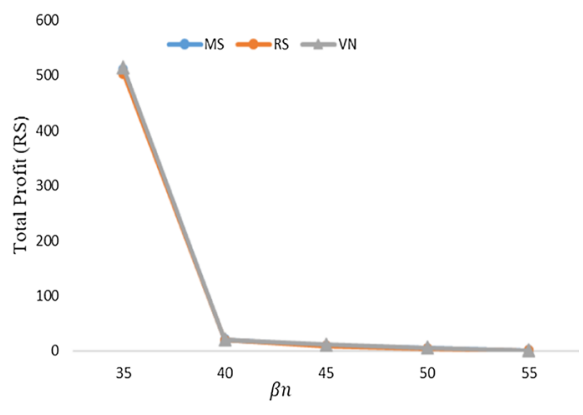

(b) Total profit for RB with different power cases value of price elasticity $(\beta)$.

Fig. 2 a.Total profit for MB with different power cases Fig. 2b. Total profit for RB with different power cases 


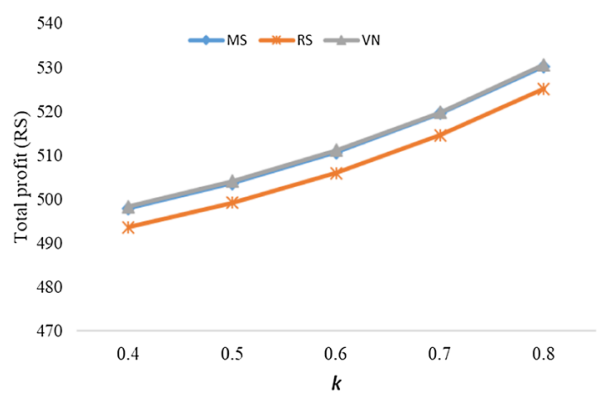

(a) Total profit for MB with different power cases different values of $k$.

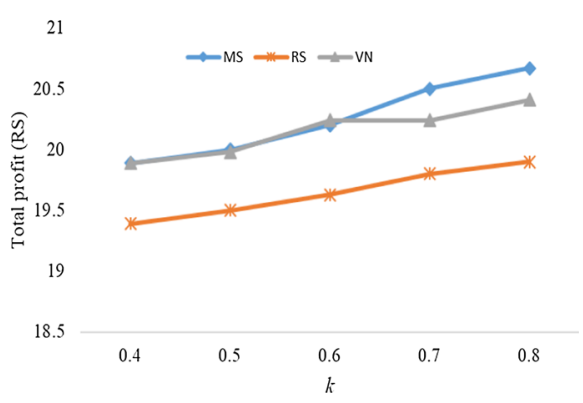

(b) Total profit for RB with different power cases different values of $k$.

Fig. 3 a.Total profit for MB with different power cases Fig. 3b.Total profit for RB with different power cases different values of $k$. different values of $k$

total profit in MS under retailer and manufacturer bundling decreases as $\beta$ increases. It is marginally higher for $\mathrm{VN}$ compared to that of RS because of the low wholesale price. Furthermore, the cost of component products will be low, and the retailer will sell those products at a higher price after bundling. As a result, the demand for bundled products will decrease as $\beta$ increases, thus leading to an increase in the total supply chain's profit. Seldom, efficiency loss due to double marginalisation is limited in the MS and VN power case under retail bundling. Furthermore, RS bundling chooses not to serve the retailer with component products. From Fig. 2a, b, it is observed that, in the VN and MS power case, the total supply chain profit under manufacturer bundling dominates that under retailer bundling; whenever the retailer offers the bundling product and advertising efforts.

\subsubsection{Impact of advertising elasticity}

Impact of advertising elasticity, $k$, on the total chain profit for three equilibrium cases under manufacturer and retailer bundling is studied. The results presented in Fig. 3a, b show that the total profit is nearly the same, as the value of advertising elasticity increases in retail and manufacturer bundling. When $k$ increases, the retailer bundling generates lower profit compared to manufacturer bundling due to low advertising effort and high bundling margin. Furthermore, the retailer motivates the consumer to purchase component products due to their proximity to the end-customer. The retailer thinks that consumers prefer bundled products more as they treat them as discount products. Therefore, among these three power systems, the best option is to use retailer bundling, whenever the retailer offers the bundled product and uses appropriate advertising effort.

\section{Conclusion and contribution}

In this paper, the impact of bundling and advertisement strategy on total channel profit in a dual manufacturer and single retailer SC network were studied. The study developed mathematical models under manufacturer bundling and retailer bundling considering three power-balance structures. Considering bundling homogenous products, characterised equilibrium outcomes under each strategy showed that total profit is undifferentiated under the MS case and VN cases in the retailer bundling and manufacturer bundling strategies. It is also observed that the 
total chain profit under manufacturer bundling dominates retailer bundling in the VN and RS cases. An extension of the basic model for studying the simultaneous impact of advertising efforts on total channel profit under two bundling strategies was also considered.

The study offers understanding of different advertising strategies in practice. It is found that manufacturer bundling is affected more by advertising effort compared to retailer bundling. The retailer spends more on component products and wants to sell all the products to maximise the profit. When advertising effort level is constrained, the study by Yan et al. (2014) showed that offering bundling products could bring equilibrium under retailer bundling. Manufacturer bundling dominates retailer bundling (particularly in RS and VN case) in terms of the total supply chain profit being unique and remains valid under various scenarios of market size, price elasticity and advertising elasticity. These models can be limited for the service types of bundling as service bundling is defined as the quadratic function of service cost.

The paper makes an original contribution to the research interfacing supply chain and marketing by considering multiple parametric conditions and scenarios. To the best of authors' knowledge, this is the first study to consider bundling and advertisement strategy simultaneously to capture insights into price competition under different power-balance scenarios. Some of the key implications of this research are as follows. First, the study showed that the optimal outcome under manufacturer bundling in the presence of double marginalisation can be different from retailer bundling. Second, the study compared manufacturer and retailer bundling strategies in terms of total supply chain profit under various power structures (such as MS, RS and VN) and showed that total supply chain profit is more in VN and MS power-balance competition under retailer bundling and manufacturer bundling compared to RS cases. Third, the total supply chain profit increases as advertising expenditure increases under the RS and VN cases in the retailer and, subsequently, manufacturer bundling is established. Fourth, it is observed that in the RB case, the retailer takes no interest in spending a significant amount on advertising for selling the bundling products. The retailer produces the bundling product on the basis of customer request. Numerical examples further illustrate and confirm the analytical findings which, in turn, offer practical insights to firm managers. In addition, the findings can help manufacturers to identify the bundling price and advertising expenditure.

Taking a lead from this study, there are several potential directions for future research. Consideration of nonlinear price and service sensitive demand function remains unexplored in the literature and models discussed in this paper can be re-examined considering these conditions. Market demand and collection rate depend on consumer attitude, whereas advertisement impacts positively on consumers' attitudes for buying bundling products; this insight can be useful for studying the impact of consumers' behavioural aspects on advertising in the future. In this paper it was assumed that the manufacturer and retailer sell only product bundling to the customer. Meanwhile, retailer and manufacture sell product bundling and component product simultaneously with a different price to the customer. It would be interesting to consider both product bundling and component products simultaneously under perfect price and service competition. The current formulation does not present the characteristics of product bundles. Future research can be extended by considering these perspectives.

The products can also be bundled with various services such as core services. Thus, this study can be extended by considering the product-service bundling strategy under a competitive environment. Furthermore, future research can highlight different cost constraints between the direct and retail channels, while investigating the return problem of bundling. It would also be interesting to understand the effect of the return policy of a bundling product on total supply chain profit while considering power-balance perspectives. 
Acknowledgements Authors would also like to thank three reviewers and special issue guest editor for their constructive recommendations for improving the quality of manuscript.

Open Access This article is licensed under a Creative Commons Attribution 4.0 International License, which permits use, sharing, adaptation, distribution and reproduction in any medium or format, as long as you give appropriate credit to the original author(s) and the source, provide a link to the Creative Commons licence, and indicate if changes were made. The images or other third party material in this article are included in the article's Creative Commons licence, unless indicated otherwise in a credit line to the material. If material is not included in the article's Creative Commons licence and your intended use is not permitted by statutory regulation or exceeds the permitted use, you will need to obtain permission directly from the copyright holder. To view a copy of this licence, visit http://creativecommons.org/licenses/by/4.0/.

\section{Appendix 1}

$$
\frac{\partial w^{M}}{\partial k}=\frac{\partial w^{R}}{\partial k}=\frac{A}{2 \beta_{n}-\gamma_{n}}>0, \text { Where } A \text { and } \beta_{n}>0
$$

\section{Appendix 2}

$$
\begin{aligned}
\frac{\partial m^{M}}{\partial A} & =\frac{-k}{2\left(\beta_{n}-\gamma_{n}\right)} \\
\frac{\partial m^{R}}{\partial A} & =\frac{k}{2\left(\beta_{n}-\gamma_{n}\right)}
\end{aligned}
$$

Observation 1.

$$
\begin{aligned}
& p_{B}^{M S R}-w_{B}^{M S M}=3 c_{B}+\frac{\theta \alpha_{n}\left(3 \beta_{n}+2 \gamma_{n}\right)+c_{B} \beta_{n}\left(k^{2}-\theta \beta_{n}+\theta \gamma_{n}\right)}{4 \theta \beta_{n}^{2}+2 \theta \gamma_{n}^{2}-\beta_{n}\left(k^{2}+6 \theta \gamma_{n}\right)} \geq 0 \\
& w_{B}^{R S M}-p_{B}^{R S R}=\frac{4 \theta \alpha_{n}\left(-\beta_{n}+\gamma_{n}\right)-4 c_{B}\left(\beta_{n}\left(3 k^{2}-4 \theta \beta_{n}\right)+\left(k^{2}+4 \theta \beta_{n}\right) \gamma_{n}\right)}{-7 \theta \beta_{n}^{2}+6 \beta_{n}\left(k^{2}+\theta \gamma_{n}\right)+\gamma_{n}\left(2 k^{2}+\theta \gamma_{n}\right)}<0 \\
& \text { because of } \gamma_{n}-\beta_{n}<0 \\
& w_{B}^{V N M}-p_{B}^{V N R}<\frac{\theta \alpha_{n}\left(-2 \beta_{n}+\gamma_{n}\right)+c_{B} \beta_{n}\left(k^{2}-\theta \beta_{n}+\theta \gamma_{n}\right)}{3 \theta \beta_{n}^{2}+\theta \gamma_{n}^{2}-\beta_{n}\left(k^{2}+4 \theta \gamma_{n}\right)}<0 \\
& A^{M S R}-A^{M S M}<\frac{k\left(\alpha_{n}+c_{B}\left(-\beta_{n}+\gamma_{n}\right)\right)\left(-3 \theta \beta_{n}^{2}+\gamma_{n}\left(k^{2}+\theta \gamma_{n}\right)+\beta_{n}\left(k^{2}+2 \theta \gamma_{n}\right)\right)}{\left(k^{2}-2 \theta \beta_{n}+2 \theta \gamma_{n}\right)\left(-5 \theta \beta_{n}^{2}+\gamma_{n}\left(k^{2}-\theta \gamma_{n}\right)+\beta_{n}\left(k^{2}+6 \theta \gamma_{n}\right)\right)}<0 \\
& A^{R S R}-A^{R S M}=k \beta_{n}\left(\frac{-2 \alpha_{n}+c_{B}\left(\beta_{n}-\gamma_{n}\right)}{3 \theta \beta_{n}^{2}+\theta \gamma_{n}^{2}-2 \beta_{n}\left(k^{2}+2 \theta \gamma_{n}\right)}+\frac{\alpha_{n}+c_{B}\left(-\beta_{n}+\gamma_{n}\right)}{4 \theta \beta_{n}^{2}+2 \theta \gamma_{n}^{2}-\beta_{n}\left(k^{2}+6 \theta \gamma_{n}\right)}\right)<0 \\
& A^{V N M}-A^{V N R}=k \beta_{n}\left(\frac{4 \alpha_{n}+2 c_{B}\left(-\beta_{n}+\gamma_{n}\right)}{5 \theta \beta_{n}^{2}+\theta \gamma_{n}^{2}-2 \beta_{n}\left(2 k^{2}+3 \theta \gamma_{n}\right)}+\frac{\alpha_{n}+c_{B}\left(-\beta_{n}+\gamma_{n}\right)}{3 \theta \beta_{n}^{2}+\theta \gamma_{n}^{2}-\beta_{n}\left(k^{2}+4 \theta \gamma_{n}\right)}\right)>0
\end{aligned}
$$

Observation 2.

Same as observation.

\section{References}

Adomavicius, G., Bockstedt, J., \& Curley, S. P. (2015). Bundling effects on variety seeking for digital information goods. Journal of Management Information Systems, 31(4), 182-212. 
Ailawadi, K. L., Borin, N., \& Farris, P. W. (1995). Market power and performance: A cross-industry analysis of manufacturers and retailers. Journal of Retailing, 71(3), 211-248.

Ali, S. M., Rahman, M. H., Tumpa, T. J., Moghul Rifat, A. A., \& Paul, S. K. (2018). Examining price and service competition among retailers in a supply chain under potential demand disruption. Journal of Retailing and Consumer Services, 40, 40-47.

Arora, R. (2008). Price bundling and framing strategies for complementary products. Journal of Product \& Brand Management, 17(7), 475-484.

Bakos, Y., \& Brynjolfsson, E. (1999). Bundling information goods: Pricing, profits, and efficiency. Management Science, 45(12), 1613-1630.

Banciu, M., Gal-Or, E., \& Mirchandani, P. (2010). Bundling strategies when products are vertically differentiated and capacities are limited. Management Science, 56(12), 2207-2223.

Baykasoğlu, A., Gölcük, İ., \& Akyol, D. E. (2017). A fuzzy multiple-attribute decision making model to evaluate new product pricing strategies. Annals of Operations Research, 251(1-2), 205-242.

Beheshtian-Ardakani, A., Fathian, M., \& Gholamian, M. (2018). A novel model for product bundling and direct marketing in e-commerce based on market segmentation. Decision Science Letters, 7(1), 39-54.

Cao, Q., Geng, X., \& Zhang, J. (2015). Strategic role of retailer bundling in a distribution channel. Journal of Retailing, 91(1), 50-67.

Cao, X., \& Ke, T. T. (2019). Cooperative search advertising. Marketing Science, 38(1), 44-67.

Cataldo, A., \& Ferrer, J. C. (2017). Optimal pricing and composition of multiple bundles: A two-step approach. European Journal of Operational Research, 259(2), 766-777.

Chakraborty, T., Chauhan, S. S., Awasthi, A., \& Bouzdine-Chameeva, T. (2018). Two-period pricing and ordering policy with price-sensitive uncertain demand. Journal of the Operational Research Society, 70, $1-18$.

Chakravarty, A., Grewal, R., \& Sambamurthy, V. (2013). Information technology competencies, organizational agility, and firm performance: Enabling and facilitating roles. Information Systems Research, 24(4), 976-997.

Chen, Y. (1997). Equilibrium product bundling. Journal of Business, 70(1), 85-103.

Chen, X., \& Wang, X. (2015). Free or bundled: Channel selection decisions under different power structures. Omega, 53, 11-20.

Choi, S. C. (1991). Price Competition in a Channel Structure with a Common Retailer. Marketing Science, 10(4), 271-296. https://doi.org/10.1287/mksc.10.4.271.

Choi, S. C. (1996). Price competition in a duopoly common retailer channel. Journal of Retailing, 72(2), 117-134.

Giri, R. N., Mondal, S. K., \& Maiti, M. (2020). Bundle pricing strategies for two complementary products with different channel powers. Annals of Operations Research, 287, 701-725.

Girju, M., Prasad, A., \& Ratchford, B. T. (2013). Pure components versus pure bundling in a marketing channel. Journal of Retailing, 89(4), 423-437.

Godes, D., Ofek, E., \& Sarvary, M. (2009). Content vs. advertising: The impact of competition on media firm strategy. Marketing Science, 28(1), 20-35.

Hanson, W., \& Martin, R. K. (1990). Optimal bundle pricing. Management Science, 36(2), 155-174.

He, X., Krishnamoorthy, A., Prasad, A., \& Sethi, S. P. (2011). Retail competition and cooperative advertising. Operations Research Letters, 39(1), 11-16.

Heydari, J., Heidarpoor, A., \& Sabbaghnia, A. (2020). Coordinated non-monetary sales promotions: Buy one get one free contract. Computers \& Industrial Engineering, 141, 106381.

Hong, X., Xu, L., Du, P., \& Wang, W. (2015). Joint advertising, pricing and collection decisions in a closed-loop supply chain. International Journal of Production Economics, 167, 12-22.

Huang, Z., Li, S. X., \& Mahajan, V. (2002). An analysis of manufacturer-retailer supply chain coordination in cooperative advertising. Decision Sciences, 33(3), 469-494.

Hui, W., Yoo, B., Choudhary, V., \& Tam, K. Y. (2012). Sell by bundle or unit? Pure bundling versus mixed bundling of information goods. Decision Support Systems, 53(3), 517-525.

Hurkens, S., Jeon, D. S., \& Menicucci, D. (2019). Dominance and competitive bundling. American Economic Journal: Microeconomics, 11(3), 1-33.

Jeitschko, T. D., Jung, Y., \& Kim, J. (2017). Bundling and joint marketing by rival firms. Journal of Economics \& Management Strategy, 26(3), 571-589.

Jena, S. K., \& Sarmah, S. P. (2014). Price competition and co-operation in a duopoly closed-loop supply chain. International Journal of Production Economics, 156, 346-360.

Jena, S. K., Sarmah, S. P., \& Sarin, S. C. (2017). Joint-advertising for collection of returned products in a closed-loop supply chain under uncertain environment. Computers and Industrial Engineering, 113, 305-322. 
Koschat, M. A., \& Putsis, W. P. (2002). Audience characteristics and bundling: A hedonic analysis of magazine advertising rates. Journal of Marketing Research, 39(2), 262-273.

Lancioni, R., Schau, H. J., \& Smith, M. F. (2005). Intraorganizational influences on business-to-business pricing strategies: A political economy perspective. Industrial Marketing Management, 34(2), 123-131.

Li, M., Feng, H., Chen, F., \& Kou, J. (2013). Numerical investigation on mixed bundling and pricing of information products. International Journal of Production Economics, 144(2), 560-571.

Lin, X., Zhou, Y. W., Xie, W., Zhong, Y., \& Cao, B. (2020). Pricing and product-bundling strategies for ecommerce platforms with competition. European Journal of Operational Research, 283(3), 1026-1039.

Liu, B., Cai, G., \& Tsay, A. A. (2014). Advertising in asymmetric competing supply chains. Production and operations management. Production and Operations Management, 23(11), 1845-1858.

Liu, Y., Wang, X., \& Ren, W. (2020). A bundling sales strategy for a two-stage supply chain based on the complementarity elasticity of imperfect complementary products. Journal of Business \& Industrial Marketing (in press).

Lu, J. C., Tsao, Y. C., \& Charoensiriwath, C. (2011). Competition under manufacturer service and retail price. Economic Modelling, 28(3), 1256-1264.

Ma, J., Ai, X., Yang, W., \& Pan, Y. (2019). Decentralization versus coordination in competing supply chains under retailers' extended warranties. Annals of Operations Research, 275(2), 485-510.

Ma, M., \& Mallik, S. (2017). Bundling of vertically differentiated products in a supply chain. Decision Sciences, 48(4), 625-656.

Mahajan, S., \& Van Ryzin, G. (2001). Inventory competition under dynamic consumer choice. Operations Research, 49(5), 646-657.

McCardle, K. F., Rajaram, K., \& Tang, C. S. (2007). Bundling retail products: Models and analysis. European Journal of Operational Research, 177(2), 1197-1217.

Mesak, H. I., \& Darrat, A. F. (1993). A competitive advertising model: Some theoretical and empirical results. Journal of the Operational Research Society, 44(5), 491-502.

Meyer, J., \& Shankar, V. (2016). Pricing strategies for hybrid bundles: Analytical model and insights. Journal of Retailing, 92(2), 133-146.

Opornsawad, C., Srinon, R., \& Chaovalitwongse, W. (2013). Competing suppliers' under-price-sensitive demand with a common retailer. In Proceedings of the world congress on engineering, I, London, UK.

Pan, X. A., \& Honhon, D. (2012). Assortment planning for vertically differentiated products. Production and Operations Management, 21(2), 253-275.

Prasad, A., Venkatesh, R., \& Mahajan, V. (2015). Product bundling or reserved product pricing? Price discrimination with myopic and strategic consumers. International Journal of Research in Marketing, 32(1), $1-8$.

Pun, H. (2015). The more the better? Optimal degree of supply-chain cooperation between competitors. Journal of the Operational Research Society, 66(12), 2092-2101.

Roy, A., Sana, S. S., \& Chaudhuri, K. (2018). Optimal pricing of competing retailers under uncertain demand-a two layer supply chain model. Annals of Operations Research, 260(1-2), 481-500.

Schmalensee, R. (1982). Commodity bundling by single-product monopolies. The Journal of Law and Economics, 25(1), 67-71.

Stremersch, S., \& Tellis, G. J. (2002). Strategic bundling of products and prices: A new synthesis for marketing. Journal of Marketing, 66(1), 55-72.

Taleizadeh, A. A., Cárdenas-Barrón, L. E., \& Sohani, R. (2019). Coordinating the supplier-retailer supply chain under noise effect with bundling and inventory strategies. Journal of Industrial \& Management Optimization, 15(4), 1701-1727.

Tsay, A., \& Agrawal, N. (2000). Channel dynamics under price and service competition. Manufacturing \& Service Operations Management, 2(4), 372-391.

Vamosiu, A. (2018). Optimal bundling under imperfect competition. International Journal of Production Economics, 195, 45-53.

Willart, S. P. (2015). Price competition in retailing: The importance of the price density function. Journal of Retailing and Consumer Services, 26, 125-132.

Xu, Q., Xu, B., Wang, P., \& He, Y. (2018). Bundling strategies for complementary products in a horizontal supply chain. Kybernetes, K-02-2017-0082.

Yan, R., Myers, C., Wang, J., \& Ghose, S. (2014). Bundling products to success: The influence of complementarity and advertising. Journal of Retailing and Consumer Services, 21(1), 48-53.

Yenipazarli, A. (2015). A road map to new product success: Warranty, advertisement and price. Annals of Operations Research, 226(1), 669-694.

Yuan, Y., Caulkins, J. P., \& Roehrig, S. (1998). The relationship between advertising and content provision on the Internet. European Journal of Marketing, 32(7/8), 677-687. 
Yue, J., Austin, J., Wang, M.-C., \& Huang, Z. (2006). Coordination of cooperative advertising in a two-level supply chain when manufacturer offers discount. European Journal of Operational Research, 168(1), 65-85.

Zhang, Z., Luo, X., Kwong, C. K., Tang, J., \& Yu, Y. (2019). Return and refund policy for product and core service bundling in the dual-channel supply chain. International Transactions in Operational Research, 26(1), 223-247.

Zhou, J. (2017). Competitive bundling. Econometrica, 85(1), 145-172.

Zhou, S., Song, B., \& Gavirneni, S. (2020). Bundling decisions in a two-product duopoly-Lead or follow? European Journal of Operational Research, 284(3), 980-989.

Publisher's Note Springer Nature remains neutral with regard to jurisdictional claims in published maps and institutional affiliations. 